\title{
The Effectiveness of the Information, Communication, and Education Model for Balance Diet and Against Stunting in the First 1000 Days of Life: A Literature Review
}

\author{
Basri Aramico $^{1 *}$, Emy Huriyati ${ }^{2}$, Susetyowati Susetyowati ${ }^{3}$, Fatwa Sari Tetra Dewi ${ }^{4}$ \\ ${ }^{1}$ Doctoral Program, Faculty of Medicine, Public Health, and Nursing, Universitas Gadjah Mada, Yogyakarta, Indonesia; \\ ${ }^{2}$ Department of Health and Nutrition, Faculty of Medicine, Public Health, and Nursing, Universitas Gadjah Mada Yogyakarta, \\ Indonesia; ${ }^{3}$ Department of Health and Nutrition, Faculty of Medicine, Public Health, and Nursing, Universitas Gadjah Mada \\ Yogyakarta, Indonesia; ${ }^{4}$ Department of Health Behavior, Environment, and Social Medicine, Faculty of Medicine, Public Health, \\ and Nursing, Universitas Gadjah Mada Yogyakarta, Indonesia
}

\section{Abstract}

Edited by: Sasho Stolesk Citation: Aramico B, Huriyati E, Susetyowati, Dewi FS. The Effectiveness of the Information, Communication and Education Model for Balance Diet and Against Stunting in the First 1000 Days of Life: A Literature Review. Open Access Maced J Med Sci. 2020 Oct 08; 8(F):226-233. https:// doi.org/10.3889/oamjms.2020.432 Keywords: Stunting; Information; Communication;
Education; Golden age *Corresponding author: Basri Aramico, Jalan tas Muhammadiyah, Aceh, 23248; Jalan Farmako Sekip Utara, Faculty of Medicine, Public Health, and Nursing, Universitas Gadjah Mada, Yogyakarta, Indonesia 55284. E-mail: basri.aramico@yahoo.com Received: 19-Jan-2020 Revised: $15-\mathrm{Sep}-2020$ Copyright: ๑ 2020 Basri Aramico, Emy Huriyati Susetyowati Susetyowati, Fatwa Sari Tetra Dew Funding: This research did not receive any financia Competing Interests: The authors have declared that no competing interest exis Open Access: This is an open-access article distributed under the terms of the Creative Commons Attribution-
BACKGROUND: The important reason why the first 1000 days are a vulnerable period is that this is a time of very rapid growth and development for a child. One of the efforts to increase this awareness concerning child growth and development is information, communication, and education (ICE).

AIM: This study was performed to determine the effectiveness of the ICE model for nutritional against stunting in the first 1000 days of life.

METHODS: This study used a literature review of published research articles on the effectiveness of the ICE mode for nutritional against stunting in the first 1000 days of life published between December 2010 and December 2018 in PubMed and Proquest online article database. Data collection techniques by entering keywords in the database keywords used: Intervention AND Model OR Media AND health promotion*health-promoting OR health education OR health information OR health communication*health communicating AND golden age OR first 2 years AND infant OR child AND maternal AND parenting AND diet OR nutritional status AND stunting.

RESULTS: This study investigated 682 articles. There were six articles included in the literature review. The results showed that to design or develop the ICE model, it is important to pay attention and consider several elements of communication such as promoters (mediators of message delivery); the content of messages, medias or model of message deliveries, message delivery techniques, and the session or frequency of message deliveries.

CONCLUSION: This study confirmed an effectiveness of the ICE model for nutritional against stunting in the first 1000 days of life.

\section{Introduction}

Stunting is a long-term impact arising from malnutrition which can cause a decrease in productivity in the next period [1]. The number of stunting children in the world reaches 155 million with the stunting prevalence is $23 \%$. Asia is the region with the stunting biggest figure in the world. Two of five stunting children live in South Asian. In 2016, the prevalence of stunting in Asia was 56\% [2], in 2018, the prevalence of stunting and severe stunting in Indonesia was $29,9 \%$ [3]. Stunting provides another impact on the next life, which among others can inhibit impaired cognitive development and physical ability, which causes a decrease in productivity to reduce the economic progress of a country at least $8 \%$ [4]. An increased risk of stunting occurs during the first 1000 days of life [5].

The critical period of improvement in children's physical and cognitive development begins from the first 1000 days of life, which starts from the time of conception until the child is 2 years old. The nutritional status of pregnant, good health status and nutritional intake are important factors for the growth, physical, and cognitive development of children, reducing the risk of morbidity in infants and mothers. Pregnant women with poor nutritional status will cause impaired fetal growth, the main cause of stunting, and increase the risk of obesity and degenerative diseases in adulthood [6]. Improving food consumption patterns is very important to prevent malnutrition [7]. Furthermore, the lack of nutrition is an initial response to the lack of energy intake of nutrients compared to needs, or an infection that causes weight loss or weight according to age is less than it should be. If this condition does not immediately get an appropriate intervention, it will be followed by a lack of linear growth (toddlers becoming shorter than they should be) or stunting [8].

Mothers and babies need adequate and quality nutrition to guarantee the nutritional status and 
health status, motoric, social and cognitive abilities, learning ability, and productivity in the future. Children with malnutrition during the first 1000 days period will experience neurological problems, decreased learning ability, increased risk of drop out from school, decreased productivity and workability, decreased income, decreased ability to provide nutritious food, and decreased parenting abilities. Next will be the regeneration of malnutrition and poverty in the next generation [9].

Optimal nutritional intake at 1000 days of life is very important and has an impact on nutritional status and health in the next period, so nutrition intervention at 1000 days of life is a top priority to improve the quality of life for the future generations. It is interventions focused on two types of interventions, namely, specific nutrition and sensitive nutrition interventions. Specific nutrition interventions are a series of activities that are quite cost-effective, especially to overcome short nutrition problems, while sensitive nutrition interventions are various development program activities that affect the nutritional status of the community, especially 1000 days of life groups, such as poverty alleviation, education, gender, clean water, sanitation, and environmental health [6].

The effort for improved nutritional status of infants in the period of 1000 days of life, in addition to being able to carry out nutrition ICE as an intervention for food consumption and nutrition, the nutrition ICE implementation program about food consumption and nutrition interventions, which aims to improve nutritional status have not been reached to the maximum, this is indicated by the high prevalence of undernutrition, poor nutrition, over-nutrition, and chronic malnutrition (stunting).

\section{Materials and Methods}

\section{Methods}

This research is literature review design. The literature review followed the preferred reporting items for Systematic Reviews and Meta-Analysis (PRISMA) statement. Literature review was used to know the effectiveness of the information, communication, and education (ICE) model for nutritional against stunting in the first 1000 days of life. The research articles samples were published between December 2010 and December 2018 in online article databases of PubMed and ProQuest.

\section{Data collection technique}

Data collection techniques by entering keywords in the database, keywords used: Intervention
AND Model OR Media AND health promotion*healthpromoting OR health education OR health information OR health communication*health communicating AND golden age OR first 2 years AND infant OR child AND maternal AND parenting AND diet OR nutritional status AND stunting. The articles limited only English articles that are available free full text. The steps are as follows at the beginning of the search researchers conducted a review based on the relevant research title, followed by a review based on the abstract and then reviewed based on the contents of the article. Research procedure is shown in Figure 1.

\section{Data analysis}

Two-independent investigators carefully extracted information from all studies that fulfilled the inclusion criteria in accordance with a standardized protocol.

\section{Results}

This study investigated 682 articles. There were five articles included in literature review. From the review, nutrition promotion (IEC) programs carried out in various regions were arranged by adjusting several factors including: mediators (promoters) delivery of messages; media; material or message; and frequency of message delivery [7]. Other elements of the education program are adjusting, namely: Media use techniques and message delivery time [10]. Furthermore, educational techniques, messages, and educators can increase the effectiveness of educational interventions [11]. Then, mediators, techniques, and promotion sessions need to be considered for effective education strategies [12]. In delivering health promotion it is necessary to consider the following things to be able to achieve targets effectively, including: How to convey the message; educational media: The frequency (sessions) of delivering messages; how effective message delivery techniques; and the content and suitability of the message delivered [13]. Other things that need to be considered so that health promotion (IEC) is the education model adapted to the session, message, and educational techniques [14].

The results showed that design or construct the ICE model it is necessary to pay attention and consider several elements of communication were promoters (mediators of message delivery); message content, media or model of message delivery, message delivery techniques, and the session or frequency of message delivery. The identification of the published articles related to the effectiveness of the ICE model for balance diet and against stunting in the first 1,000 days of life (Table 1). 


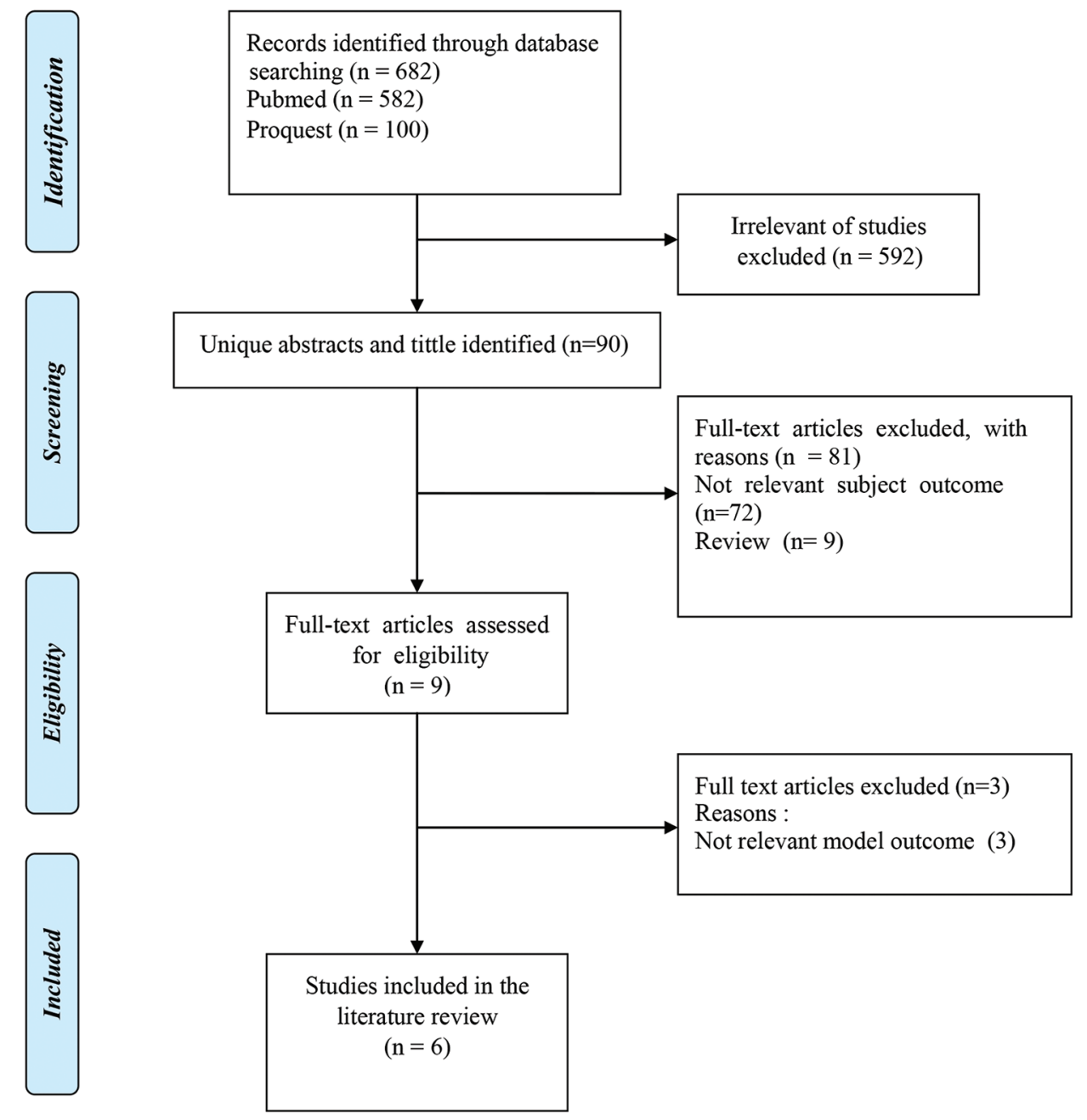

Figure 1: Flow diagram of research procedure

\section{Discussion}

\section{Promoter (Mediator of message delivery)}

Counseling or delivery of nutrition and health messages can be delivered by or through health cadres who are also often referred to as community health workers (CHWs) who have been trained previously. In delivering health messages, cadres are monitored and monitored by two layers of field supervisors Field Supervisors (FSs) and Field Research Assistants (FRA). Cadres as the intervention team were given intensive counseling training in three phases, and monthly meetings were held to solve problems related to obstacles in the field. Monitors provide daily feedback to the relevant $\mathrm{CHW}$ during counseling supervision on site [11]. The previous study conducted a systematic review of family and household-based interventions, from the results of the review, concluded that more interventions must be developed that target parents as the main agents of behavior change [15].

Another study, in a study also involved health cadres in a nutrition education intervention program in rural Cambodia. Health cadres who are trained in delivering nutrition education programs to the public are called community nutrition promoters (CNP). The main objective of this research is to assess the impact of nutrition education programs to improve the practice of eating infants and children under the age of 2 years, by combining agricultural interventions with training on child feeding through the health-care approach as a health promoter [13]. Health cadres can be involved as facilitators in delivering educational messages to increase mother's knowledge [16].

Knowledge and behavior factors of parents are related to children's diets, parent factors are very important in determining children's nutritional behavior. Mother's self-efficacy in child feeding has shown an association with children's higher vegetable intake and decreased non-core food intake [17]. Higher maternal knowledge about child feeding message intervention, mediates the influence on the child's food quality so that parental knowledge is very important as an element of community health nutrition interventions [7].

Education to improve maternal union can be done by training health cadres, as promoters of delivery of messages. The previous study found the effectiveness of training provided to groups of field workers (health 
Table 1: Literature review of the effectiveness of the information, communication, and education model for balance diet and against stunting in the first 1000 days of life

\begin{tabular}{|c|c|c|c|c|}
\hline Author & Region & Title & Method & Model Elements \\
\hline $\begin{array}{l}\text { Wen et al. } \\
{[10]}\end{array}$ & $\begin{array}{l}\text { New South } \\
\text { Wales (NSW) } \\
\text { Australia }\end{array}$ & $\begin{array}{l}\text { A 3-Arm randomized controlled } \\
\text { trial of } \\
\text { Communicating Healthy Beginnings } \\
\text { Advice by Telephone (CHAT) to } \\
\text { mothers with infants to prevent } \\
\text { childhood obesity }\end{array}$ & $\begin{array}{l}\text { Randomized controlled trial; } \\
\text { Nutrition education intervention } \\
\text { (consultation) for pregnant women } \\
\text { weeks } 28 \text { and } 34 \text { up to } 12 \text { months } \\
\text { after birth for obesity in children }\end{array}$ & $\begin{array}{l}\text { Promoter: Nurse of nutrition } \\
\text { Media: Telephone and chat } \\
\text { Message contents: Duration of breastfeeding introduction and complementary } \\
\text { foods }\end{array}$ \\
\hline $\begin{array}{l}\text { Billah } \\
\text { et al. [11] }\end{array}$ & Bangladesh & $\begin{array}{l}\text { A community-based cluster } \\
\text { randomized controlled trial to } \\
\text { evaluate the effectiveness of } \\
\text { different bundles of nutrition- } \\
\text { specific interventions in improving } \\
\text { mean length-for-age } z \text { score among } \\
\text { children at } 24 \text { months of age in } \\
\text { rural Bangladesh: study protocol }\end{array}$ & $\begin{array}{l}\text { Randomized controlled trial; } \\
\text { Intervention changes in nutrition } \\
\text { fulfillment behavior for pregnant } \\
\text { women, breastfeeding, and its } \\
\text { impact on nutritional status. Body } \\
\text { length according to age in children } \\
<2 \text { years }\end{array}$ & $\begin{array}{l}\text { Promoter: community health workers (CHWs) } \\
\text { Methods: combines three main message types, including: Maternal nutrition } \\
\text { during pregnancy; Exclusive breastfeeding; and suitable foods for ages } 6-23 \\
\text { months. } \\
\text { Technique: Intensive counseling every month until } 6 \text { months old by direct } \\
\text { demonstration; after } 6 \text { months of age counseling is done every } 3 \text { months }\end{array}$ \\
\hline $\begin{array}{l}\text { Reinbott } \\
\text { et al. [13] }\end{array}$ & Cambodia & $\begin{array}{l}\text { Nutrition education linked to } \\
\text { agricultural interventions improved } \\
\text { child dietary } \\
\text { diversity in rural Cambodia }\end{array}$ & $\begin{array}{l}\text { Randomized controlled trial; } \\
\text { behavior change intervention } \\
\text { with nutrition education and } \\
\text { measurement of nutritional status } \\
\text { of body length/age }\end{array}$ & $\begin{array}{l}\text { Promoter: used a community nutrition promoter training approach } \\
\text { Media: Used a flipchart developed by UNICEF } 2012 \\
\text { Session: Seven nutrition education sessions } 2-4 \text { h every week or fortnight }\end{array}$ \\
\hline $\begin{array}{l}\text { Nair et al. } \\
\text { [12] }\end{array}$ & Eastern India & $\begin{array}{l}\text { Participatory women's groups and } \\
\text { counseling through home visits } \\
\text { to improve child growth in rural } \\
\text { eastern India: Protocol for a cluster } \\
\text { randomized controlled trial }\end{array}$ & $\begin{array}{l}\text { Randomized controlled trial; } \\
\text { Educational and counseling } \\
\text { interventions in third trimester } \\
\text { pregnant women }\end{array}$ & $\begin{array}{l}\text { Mediator: community nutrition Promoters (CNP) } \\
\text { Technique: home visits } \\
\text { Session: Seven time points: During pregnancy, within } 72 \mathrm{~h} \text { of delivery, and at } \\
3,6,9,12 \text {, and } 18 \text { months after birth }\end{array}$ \\
\hline $\begin{array}{l}\text { Spence } \\
\text { et al. [7] }\end{array}$ & $\begin{array}{l}\text { Melbourne, } \\
\text { Australia }\end{array}$ & $\begin{array}{l}\text { Mediators of improved child diet } \\
\text { quality } \\
\text { following a health promotion } \\
\text { intervention: the Melbourne InFANT } \\
\text { Program }\end{array}$ & $\begin{array}{l}\text { Randomized controlled trial; } \\
\text { Maternal knowledge intervention } \\
\text { about breastfeeding practice on } \\
\text { weight growth (BMI) }\end{array}$ & $\begin{array}{l}\text { Methods/ Technique: peer group discussion (maternal mediators) } \\
\text { Media: Using digital video disc (DVD) } \\
\text { Message contents: Feeding practices (pregnant and nursing mothers); self- } \\
\text { efficacy; and emphasizes parenting skills } \\
\text { Frekuension: Six interactive sessions conducted for } 15 \text { months, since children } \\
\text { are } 4 \text { months old }\end{array}$ \\
\hline $\begin{array}{l}\text { Kulwa } \\
\text { et al. [14] }\end{array}$ & Tanzania & $\begin{array}{l}\text { Effectiveness of a nutrition } \\
\text { education package in improving } \\
\text { feeding practices, dietary adequacy } \\
\text { and growth of infants and young } \\
\text { children in rural Tanzania: rationale, } \\
\text { design and methods of a cluster } \\
\text { randomized trial }\end{array}$ & $\begin{array}{l}\text { Randomized controlled trial; } \\
\text { maternal education and counseling } \\
\text { intervention on body length growth } \\
\text { according to age of children aged } \\
24 \text { months }\end{array}$ & $\begin{array}{l}\text { Message contents: maternal nutrition during pregnancy; exclusive } \\
\text { breastfeeding; and supplementary feeding suitable for ages } 6-23 \text { months } \\
\text { Technique: (1) maternal education and counseling; (2) community-based } \\
\text { nutrition counselor training and monthly home visits; (3) sensitization } \\
\text { meetings with health staff and family members; and } 4 \text { ) nutrition counseling } \\
\text { based on community counselors } \\
\text { Session: conducted } 3 \text { sessions, } 2 \text { to } 3 \text { hours in each monthly activity, the first } \\
\text { session is conducted when the baby is born until the age of } 6 \text { months; the } \\
\text { second and third sessions are conducted when babies are } 9 \text { and } 12 \text { months old }\end{array}$ \\
\hline
\end{tabular}

cadres) who are trained independently to increase maternal knowledge about supplementary feeding to infants and children and have an impact on nutritional status. However, this study suggests that additional interventions include further training to improve the performance of health cadres and skills in community mobilization. Then, the dissemination of information through the mass media must also be increased to increase the coverage of mothers in providing appropriate food for their children, following health messages promoted by health care providers so that it is more effective in reducing the risk of stunting [16].

\section{Message content}

The study of Wen et al. explains important messages that need to be conveyed during the first 1000 day period to mothers with newborns including: (a) Duration of breastfeeding, (b) time of introduction of solids, (c) nutritional behavior, physical activity, and television viewing, and (d) body weight and body mass index (BMI) scores at 12 and 24 months, (e) costeffectiveness, and (f) eligibility and acceptance of the intervention [10].

Billah et al. developed the Behavior Change Communication (BCC) Module or behavioral change communication module and tested the effectiveness of the $\mathrm{BCC}$ module package as an intervention material to increase the length-length Z-score according to age/ LAZ in children until the age of 2 years. The message content that was used as a special nutrition intervention material was adapted from WHO-UNICEF. The module combines three main message types from $\mathrm{BCC}$ including: (a) Maternal nutrition during pregnancy; (b) infant nutrition through exclusive breastfeeding; and (c) nutrition for children through the provision of suitable age-appropriate complementary food for 6-23 months [11]. The nutrition education package in the previous research, consisted of three modules which included nutrition messages, including: Orientation and introduction to the role of nutrition during the first 2 years of life; feeding practices; use of local food as a complementary food; and prevention of health problems [14].

The facilitator guide assisted the Community Nutrition Promoter (CNP) to structure the specific can used seven sessions. The content of the sessions comprised eight key messages: Continued breastfeeding, introduction of complementary foods, consistency of complementary foods, dietary diversity, feeding a sick child, responsive feeding, family nutrition, and hygiene practices [13].

\section{Media of message delivery}

Delivering health messages requires the right of media so that the content of the message 
delivered can be well received by the communicant or recipient of the message. In the sense of the media, previous study argued that "the media are not just the content they carry, but has social implications," so in conveying the message it must be known that "Media are the message" McLuhan et al. used the media, and technology to designate "an extension of ourselves." Good communication tools and their impact on content delivery [18]. Nutrition education materials can using Flipchart which was developed by the National Nutrition Programme and UNICEF in Cambodia in 2012 BabyFriendly Community Initiative (BFCl) [13].

Although the Indonesian Ministry of Health has used digital media as a medium for health promotion, in some parts of Indonesia, the integrated service programs (posyandu) are using leaflets and films (video) to convey messages about nutrition education and information. This is because of limited number of communication facilities. Health messages to parents can be conveyed through digital media, with the aim that parents can provide appropriate care for their babies. However, the use of digital media in delivering health messages must be able to consider several methodological feasibilities and the objectives of the intervention, including: The feasibility of a media to keep the target; monitoring process; possibility of getting feedback; evaluation of the intervention process; and outcome or change in outcome [19].

Furthermore, the research shows that digital media such as handheld devices (tablets) deliver messages or nutrition status measurement programs to parents when their babies are 3 months old. The research data include data (birth weight and length of the baby, current weight, height and weight of the mother and father, the smoking status of the mother during pregnancy, and breastfeeding), then the programmed digital media can calculate the baby's risk status using WHO growth charts that can be displayed on a tablet screen obstacles or obstacles in delivering digital messages using a tablet including requiring adequate internet access [19].

Media for delivering the next message can use leaflets and film media (video). The use of certain media can influence the results of health promotion interventions, and the use of one media with other media can make a difference in the results of interventions. Suhertusi et al. research results show that based on the audience's knowledge value, explaining health promotion with leaflet and film media has a different effect on the level of knowledge of pregnant women, the knowledge of pregnant women is higher after being intervened with film media (video) compared to mothers pregnant who were intervened using leaflets, with test results that amounted to 5.29:2.81. Health promotion using film media is more effective in increasing knowledge than using leaflet media [20].

Media delivery of health messages for mothers with newborns can also be done using the telephone media. Baby mothers can receive messages or information about health through telephone interventions in the form of text messages, which are sent by health workers at certain times of the third trimester of pregnancy until 12 months after birth. The message is conveyed through a database containing standard but personalized text messages (i.e., the names of participants/mothers and babies) that are developed and tested according to the specified stages. The two-way Short Message Service (SMS) will also receive and store text messages from participating mothers in an excel spreadsheet that will be reviewed every day except weekends and holidays. Common questions will be answered by SMS again within $24 \mathrm{~h}$ (except weekends) by the research nurse. Mothers in this intervention group will also receive 6 phased intervention packages through SMS followed by telephone calls from research nurses within 1-2 weeks. For each telephone contact, the nurse will spend approximately $30 \mathrm{~min}$ with the mother to go through the source of the intervention sent and discuss the problem or problem raised by the mother [10].

Nutrition education related to agricultural interventions increases the diversity of children's eating patterns in rural Cambodia, to reduce the risk of stunting in children under the age of two using posters as a medium in delivering nutrition education. Educational posters were introduced during the training and given to caregivers as a reference after the intervention. The poster facilitates the dissemination of information at the end of a nutrition education session. The contents of the poster consist of recipes for complementary foods, age-appropriate foods, sanitation and hygiene, food preparation, and seasonal food availability calendar [13].

\section{Message Delivery Model}

Zickuhr et al. mention that looking for health information, an activity that was once the primary domain of older adults is now the third most popular online activity for all internet users over 18 years of age 20. Information and other health care for sharing success stories and advice with doctors who might seek inspiration and guidance through IT technology [18].

Intervention models through SMS and telephone calls from nurses can be implemented within 1-2 weeks. At each telephone contact, the nurse can intervene for about 30 min with the mother through the source of the intervention sent and discuss the problem or concern raised by the mother. The model is based on telephone support based on available data, which contains a checklist to ensure that all information is covered. During the telephone intervention period, it is necessary to consider the practicality and sustainability 
of telephone intervention. Telephone usage sessions must be delivered by nurses or staff who have been trained in delivering messages through telephone equipment [14].

Vazir et al. use flipcharts to deliver health messages communicated by health cadres to the baby's mother. Flipcharts are designed using pictures, and the messages contained on flipcharts are adjusted or vary based on the child's age. Messages and materials are built and developed following local culture and tested so that they are easily understood and communicated. Flipchart is equipped with photographs of modeling certain behaviors that are related to the health message delivered. Each message is followed by a motivating statement, checking questions, and deniers (to ensure intended understanding and practice) [21].

Family-based interventions need to be carried out so that the different settings in which children live (home, school, and community) collaborate in influencing children in a healthy way (i.e., an integral approach). The optimal delivery model must be in accordance with the needs of parents. Some might prefer education sessions in the form of group sessions, greater intensity of interventions might be needed to achieve long-term and beneficial effects [15].

Other elements in the promotion model or ICE that need to be understood are based on the Lasswell Formula, which has been developed by several researchers in various mass communication studies, including: Communicator, source, sender; message; media (channel, media); communicant, receiver; and effect, impact, and influence [22].

\section{Messaging Techniques}

To increase the nutritional knowledge of mothers Spance et al. conducted an intervention that involved six interactive sessions over 15 months since children were around 4 months old. Sessions include educational activities using digital video discs (DVDs), health promotion through discussions with colleagues, and written material. This intervention has a primary focus on improving children's food quality (specifically promoting fruit and vegetables and discouraging noncore foods), through increasing maternal knowledge, feeding practices, self-efficacy, and role modeling. The main principles of intervention include offering anticipatory guidance, promoting the division of responsibilities in child feeding and emphasizing parenting skills [7].

Kulwa et al. tested the effectiveness of nutrition education packages to improve improving feeding practices, adequate diet and growth in body length and weight of infants and children aged 2 years, interventions carried out with routine health education offered monthly by health staff at the facility health. The intervention group will receive a nutrition education package in addition to routine health education. The education package consists of four components: (1) Mother's education and counseling; (2) communitybased nutrition counselor training and monthly home visits; (3) sensitization meetings with health staff and family members; and (4) nutrition counseling based on community counselors [14].

Family-based interventions must be developed in such a way that positive parenting practices can be promoted. Parents need to understand the practice of caring for nutrition. However, to date, it is still unclear which methods and strategies are most effective in giving parents useful tools for adopting and implementing optimal positive parenting practices. Some parents only need to confirm their current parenting behavior, while others need intensive support in how to raise their children healthy. The exact level of intervention may also depend on the child's status and temperament. Therefore, it is recommended that the intervention system be implemented at all levels of family needs [15].

Nutrition counseling can be done through regular, personalized home-based counseling by community health workers or health cadres trained in nutrition in maternal and child health. Intervention in the form of counseling tailored for mothers and infants. The intervention package is designed to help community workers or primary health workers to be able to support mothers, fathers and other caregivers to feed their babies and children optimally. Health cadres are equipped with counseling cards for infant and child feeding, using brightly colored illustrations that illustrate the concepts and behavior of feeding infants and children. Counseling begins during pregnancy and continues until the age of 1 year after birth [23].

Family-based interventions need to be done so that the different settings in which children live (home, school, and community) collaborate in healthily influencing children (i.e., an integral approach). The optimal delivery model must be following the needs of parents. Some may prefer educational sessions in the form of group sessions. Greater intervention intensity may be needed to achieve long-term and beneficial effects, while the added value of home visits and online interventions must be further investigated [15].

Delivery of nutrition messages to improve the nutritional status of children during the first 2 (two) years of life (1000 days of life) conducted by Billah et al. in Bangladesh, through the Behavior Change Communication Module (BCC), conducted during pregnancy, by conducting counseling sessions including $\mathrm{BCC}$ in nutrition during pregnancy; and sensitization to optimal breastfeeding practices. Intensive counseling and direct demonstrations are conducted every month from optimal breastfeeding 
practices (including positioning and adhesion, expression, and storage of breast milk), and nutrition for nursing mothers until babies are 6 months old. After the age of 6 months, direct counseling and demonstration sessions are conducted every 3 months, counseling includes: Preparation and optimal supplementary feeding; nutritious food according to age made from local ingredients; responsive food; continuous breastfeeding; and nutrition of the mother during breastfeeding. Additional counseling visits are carried out if requested by the respondent or if the health care considers the respondent to be able to change their current practice. As an integral part of nutrition, counseling about good hygiene and parenting practices for mothers and children is also delivered in each session [24].

\section{Frequency/Session of Message Delivery}

Health messages delivery through media such as the use of two-way SMS services enables interactivity between mothers and intervention nurses. Wen et al. research showed that the use of special resources sent through SMS, women in this intervention group will send text messages to their mobile phones automatically at a predetermined time (10:00 to 1:00) and carried out in sessions twice a week for 4 weeks. The frequency and timing of SMS are based on pilot studies. Messages will provide information/ advice, motivation/information, and encouragement (messages), psychosocial support for a healthy baby and child food and lifestyle [10].

Furthermore, Kulwa et al. through a research trial which explained that intervention sessions in the form of education and counseling for mothers and infants can be done by recruiting mothers and infants who will be given nutrition education and counseling in three sessions. The first session is conducted when the baby is born until the age of 6 months. The second and third sessions can be done when babies are 9 and 12 months old. During monthly visit interventions, it is expected that each intervention session lasts 2-3 h for each intervention activity [14]. Trained CNP together with local NGO in Cambodia, conducted seven nutrition education sessions of 2-4 h weekly or biweekly depending on the availability of the participants conducted seven nutrition education sessions of 2-4 h weekly or biweekly depending on the availability of the participants [13].

Nutrition education provided to caregivers in their homes or communities can improve the nutritional status of children under five in developing countries. From the results of the review explained that to produce the results of effective interventions, it is recommended to hold a group of caregivers and community leaders, provides education at frequent intervals, for example, twice a week and in addition to home visits, it is also advisable to conduct cooking demonstrations. From the results of the review, it was found that various effects or results were found regarding the results of interventions on the nutritional status of children. This was influenced by several factors including: Different strategies and intensity of interventions; differences in children's ages at registration: Pre-existing growth and nutritional status of children [25].

Health promotion or health education, nutrition for mothers, and children can be given at certain time points, Nair et al. intervene in health promotion for pregnant women to reduce the risk of stunting during the first 1000 days of life at seven-time points, which include: Month during the third trimester of pregnancy; in $72 \mathrm{~h}$ after giving birth; and every month when infants and children aged 3, 6, 9, 12, and 18 months after birth [12]. Meanwhile, Reinbott et al. intervene by training village volunteers called community nutrition Promoters (CNP), CNPs who are trained together with local NGOs organize seven nutrition education sessions 2-4 h every week or biweekly depending on the availability of the participants [13].

Nutrition delivery program in Indonesia is generally delivered at the time of integrated service program, the implementation is once a month but only in general and not specifically about the first 1000 day of life nutrition, this can be seen from the high stunting rate and still, there are still malnourished infants/toddlers. This illustrates the implementation of the delivery of messages, education, and nutritional information that has not been effective.

\section{Conclusions}

The design or construct the ICE model it is necessary to pay attention and consider several elements of communication were promoters (mediators of message delivery); message content, media or model of message delivery, message delivery techniques, and the session or frequency of message delivery. Nutrition ICE can not only be done by health workers but also in addition to disseminating nutritional information through mass media, it can also be done by local volunteers or health cadres who have been trained. The message must be following the information needs for pregnant women and the growth of 1000 days of life. The nutrition ICE model is adjusted based on needs and available resources or facilities. Models and media content material that is tailored to the needs of the target or intervention target. Message delivery techniques by applying available models and media with duration as needed. 


\section{References}

1. Fernald LC, Galasso E, Qamruddin J, Ranaivoson C Ratsifandrihamanana L, Stewart CP, et al. A cluster-randomized, controlled trial of nutritional supplementation and promotion of responsive parenting in Madagascar: The mahay study design and rationale. BMC Public Health. 2016;16:466. https://doi. org/10.1186/s12889-016-3097-7

\section{PMid:27255923}

2. Hawkes C, Fanzo J. Nourishing the SDGs: Global Nutrition Report. Bristol, UK: Development Initiatives Poverty Research Ltd.; 2017.

3. Kementerian Kesehatan Republik Indonesia. Riset Kesehatan Dasar. Jakarta: Badan Penelitian dan Pengembangan; 2018.

4. Maternal and Child Nutrition. The Series Identifies a Set of Ten Proven Nutrition-Specific Interventions, which if Scaled Up from Present Population Coverage to Cover $90 \%$ of the Need, Would Eliminate about 900000 Deaths of Children Younger than 5 Years in the 34 High Nutrition-Burden Countries-where 90\% of the World's Stunted Children Live, Lancet; 2013.

5. Vir SC. Improving women's nutrition imperative for rapid reduction of childhood stunting in South Asia: Coupling of nutrition specific interventions with nutrition sensitive measures essential. Matern Child Nutr. 2016;12:72-90. https://doi. org/10.1111/mcn.12255

PMid:27187909

6. Rahmawati W, Wirawan NN, Wilujeng CS, Nugroho FA, Habibie IY, Fahmi I, et al. Description of nutritional problems in in The First One Thousand Days of Llfe in Malang city and district Indonesia. Indones J Hum Nutr 2016;3(1):20-31. https://doi. org/10.21776/ub.ijhn.2016.003.suplemen.3.

7. Spence AC, Campbell KJ, Crawford DA, Mcnaughton SA, Hesketh KD. Mediators of improved child diet quality following a health promotion intervention: The melbourne InFANT program. Int J Behav Nutr Phys Act. 2014;11:137. https://doi.org/10.1186/ s12966-014-0137-5

PMid:25366542

8. Kattula D, Sarkar R, Sivarathinaswamy P, Velusamy V, Venugopal S, Naumova EN, et al. The first 1000 days of life: Prenatal and postnatal risk factors for morbidity and growth in a birth cohort in Southern India. BMJ Open. 2014;4(7):e005404. https://doi.org/10.1136/bmjopen-2014-005404

9. United States Agency for International Development. In: Shah RJ, editor. Multi Sectoral Nutrition Strategy 2014-2025. Washington, DC: United States Agency for International Development; 2014

10. Wen LM, Rissel C, Baur LA, Hayes AJ, Xu H, Whelan A, et al. A 3-Arm randomised controlled trial of communicating healthy beginnings advice by telephone (CHAT) to mothers with infants to prevent childhood obesity. BMC Public Health. 2017;17:79. https://doi.org/10.1186/s12889-016-4005-x

PMid:28088203

11. Billah SM, Ferdous TE, Karim MA, Dibley MJ, Raihana S, Moinuddin $\mathrm{M}$, et al. A community-based cluster randomised controlled trial to evaluate the effectiveness of different bundles of nutrition-specific interventions in improving mean lengthfor-age $Z$ score among children at 24 months of age in rural Bangladesh: Study protocol. BMC Public Health. 2017;17:375. https://doi.org/10.1186/s12889-017-4281-0 PMid:28464867

12. Nair N, Tripathy P, Sachdev HS, Bhattacharyya S, Gope R, Gagrai S, et al. Participatory women's groups and counselling through home visits to improve child growth in rural eastern India: Protocol for a cluster randomised controlled trial. BMC Public Health. 2015;15:384. https://doi.org/10.1186/s12889-015-1655-z PMid:25886587
13. Reinbott A, Schelling A, Kuchenbecker J, Jeremias T, Russell I, Kevanna $\mathrm{O}$, et al. Nutrition education linked to agricultural interventions improved child dietary diversity in Rural Cambodia. $\mathrm{Br} J$ Nutr. 2016;116(8):1457-68. https://doi.org/10.1017/ s0007114516003433

PMid:27702425

14. Kulwa KB, Verstraeten $R$, Bouckaert KP, Mamiro PS, Kolsteren PW, Lachat $\mathrm{C}$. Effectiveness of a nutrition education package in improving feeding practices, dietary adequacy and growth of infants and young children in Rural Tanzania: Rationale, design and methods of a cluster randomised trial. BMC Public Health. 2014;14:1077. https://doi. org/10.1186/1471-2458-14-1077 PMid:25318980

15. Gerards SM, Kremers SP. The role of food parenting skills and the home food environment in children's weight gain and obesity. Curr Obes Rep. 2015;4(1):30-6. https://doi.org/10.1007/ s13679-015-0139-x

PMid:25741454

16. Zaman S, Ashraf RN, Martines J. Training in complementary feeding counselling of healthcare workers and its influence on maternal behaviours and child growth: A cluster-randomized controlled trial in Lahore, Pakistan. J Health Popul Nutr. 2008;26(2):210-22. PMid:18686554

17. Swanson V, Hannula L, Eriksson L, Wallin MH, Strutton J. Both parents should care for babies: A cross-sectional, cross-cultural comparison of adolescents breastfeeding intentions, and the influence of shared-parenting beliefs. BMC Pregnancy Childbirth. 2017;17(1):204. https://doi.org/10.1186/s12884-017-1372-y PMid:28662687

18. DeJong SM. Blogs and Tweets, Texting and Friending: Social Media and Online Professionalism in Health Care. Amsterdam: Elsevier Inc.; 2013. p. 1-175.

19. Redsell SA, Rose J, Weng S, Ablewhite J, Swift JA, SiriwardenaAN et al. Digital technology to facilitate proactive assessment of obesity risk during infancy (ProAsk): A feasibility study. BMJ Open. 2017;7(9):e017694. https://doi.org/10.1136/bmjopen-2017-017694 PMid:28882926

20. Hendriyani $H$, Sudargo $T$, Lusmilasari L, Helmyati $S$, Susetyowat S, Nindrea RD. Complementary Feeding Self-efficacy: A Concept Analysis. Open Access Maced J Med Sci 2020;8(F):11-2.

21. Vazir S, Engle P, Balakrhisna N, Griffiths PL, Jhonson SL, Creed-Kanashiro HM, et al. Cluster-randomized trial on complementary and responsive feeding education to caregivers found improved dietary intake, growth and development among rural Indian toddlers. Matern Child Nutr. 2013;9(1):99-117. https://doi.org/10.1111/j.1740-8709.2012.00413.x PMid:22625182

22. Mcquail D, Windahl S. Communication Models for the Study of Mass Communications. $2^{\text {nd }}$ ed. London, New York: Routledge, Taylor and Francis Group; 2013.

23. Abuya BA, Ciera J, Kimani-Murage E. Effect of mother's education on child's nutritional status in the Slums of Nairobi. BMC Pediatr. 2012;12:80. https://doi.org/10.1186/1471-2431-12-80 PMid:22721431

24. Rabbani A, Khan A, Yusuf S, Adams A. Trends and determinants of inequities in childhood stunting in Bangladesh from 1996/7 to 2014. Int J Equity Health. 2016;15(1):186. https://doi. org/10.1186/s12939-016-0477-7 PMid:27852266

25. Majamanda J, Maureen D, Munkhondia TM, Carrier J. The effectiveness of community-based nutrition education on the nutrition status of under-five children in developing countries. A systematic review. Malawi Med J. 2014;26(4):115-8.

PMid:26167260 